\title{
Pelatihan Peningkatan Gizi Keluarga Sebagai Upaya Mengatasi Masalah Stunting dengan Pemanfaatan Pekarangan
}

\author{
Soni Akhmad Nulhaqim, Muhammad Fedryansyah, Maulana I rfan, Wandi \\ Adiansah
}

Program Studi Kesejahteraan Sosial, Fakultas IImu Sosial dan IImu Politik, Universitas Padjadjaran

soni.nulhaqim@unpad.ac.id, m.fedryansyah@unpad.ac.id, maulana.irfan@unpad.ac.id, adiansahw@gmail.com

\begin{abstract}
Abstrak
Kegiatan Pengabdian Kepada Masyarakat ini dilatar belakangi oleh adanya kebutuhan warga untuk melakukan sebuah kegiatan yang dapat menjadi wadah untuk berkegiatan bersama dan saling berinteraksi. Selain itu, warga di Desa Cinunuk tergolong masyarakat berpenghasilan rendah yang memiliki berbagai kerentanan. Salah satu kerentanan tersebut yaitu kerentanan pangan. Berdasarkan hal tersebut maka kegiatan PPM ini dilaksanakan dalam bentuk Pelatihan Peningkatan Gizi Keluarga Sebagai Upaya Mengatasi Masalah Stunting dengan Pemanfaatan Pekarangan di Desa Cinunuk Kecamatan Cileunyi Kabupaten Bandung. Tujuan dari dilaksanakannya kegiatan PPM ini yaitu diharapkan mampu meningkatkan pemahaman dan keterampilan kader Karang Taruna dan PKK dalam peningkatan gizi keluarga dengan pemanfaatan pekarangan rumah untuk budidaya tanaman pangan, sayuran, buah-buahan dan tanaman obat keluarga. Kedua, kegiatan ini diharapkan menjadi salah satu bentuk kegiatan bersama yang dapat dilakukan oleh warga. Ketiga, kegiatan ini juga diharapkan mampu menjadi salah satu media interaksi positif bagi warga. Tahap pelaksanaan dari kegiatan ini yaitu tahap persiapan kegiatan PPM, pemetaan wilayah pelaksanaan pelatihan (assessment), serta monitoring dan evaluasi.
\end{abstract}

Kata Kunci: stunting; masyarakat berpenghasilan rendah; penguatan kelembagaan.

\section{Abstract}

The Community Service activities are motivated by the need for residents to carry out an activity that can be a place for joint activities and interaction with each other. In addition, residents in Cinunuk Village are classified as low-income people who have various vulnerabilities. One such vulnerability is food vulnerability. Based on this, the PPM activity was carried out in the form of Family Nutrition Improvement Training as an Effort to Overcome the Stunting Problem with the Utilization of Yard in Cinunuk Village, Cileunyi District, Bandung Regency. The aim of this PPM activity is to increase the understanding and skills of the Youth Youth and PKK cadres in improving family nutrition by utilizing home yards for the cultivation of food crops, vegetables, fruits and family medicinal plants. Second, this activity is expected to be one form of joint activities that can be carried out by residents. Third, this activity is also expected to be one of the positive interaction media for the citizens. The implementation phase of this activity is the preparation phase of PPM activities, mapping the area of implementation of the training (assessment), as well as monitoring and evaluation.

Keywords: stunting; low income community; institutional strengthening.

\section{PENDAHULUAN}

Karang Taruna dan PKK merupakan salah satu lembaga kemasyarakatan yang ada di setiap RW di lingkungan Desa Cinunuk Kecamatan Cileunyi Kabupaten Bandung. Berdasarkan hasil penelitian yang telah dilakukan sebelumnya, saat ini Karang Taruna dan PKK di perumahan tersebut belum mampu mewadahi warga dalam melakukan kegiatan bersama. Kegiatan bersama yang diwadahi Karang Taruna hanya dilakukan khususnya pada moment-moment tertentu seperti pada Peringatan Hari Besar Nasional (PHBN) atau 


\begin{tabular}{|c|c|c|c|c|}
\hline $\begin{array}{c}\text { Prosiding Penelitian \& } \\
\begin{array}{c}\text { Pengabdian Kepada } \\
\text { Masyarakat }\end{array}\end{array}$ & $\begin{array}{c}\text { e ISSN : 2581-1126 } \\
\text { p ISSN : 2442-448X }\end{array}$ & Vol 5, No: 3 & Hal: 260 - 264 & Desember 2018 \\
\hline
\end{tabular}

pada Peringatan Hari Besar Islam (PHBI). Sedangkan untuk kegiatan PKK yaitu terdiri dari kegiatan Posyandu dan Pengajian. Kedua kegiatan PKK tersebut belum mampu mewadahi seluruh warga penghuni perumahan dalam melakukan kegiatan bersama. Hal ini karena kedua kegiatan PKK tersebut hanya terbatas bagi warga yang memiliki anak balita dan warga yang beragama Islam saja, sedangkan untuk warga diluar kategori tersebut belum terwadahi.

Berdasarkan temuan tersebut, tim peneliti merasa perlu untuk menyusun sebuah kegiatan yang mampu mewadahi seluruh warga penghuni perumahan dalam melakukan kegiatan bersama. Kegiatan bersama yang dilakukan oleh warga penghuni perumahan ini sangat penting karena kegiatan bersama tersebut merupakan salah satu bentuk interaksi sosial diantara sesama warga perumahan. Terlebih ketika kegiatan bersama yang dilakukan merupakan kegiatan yang mengarah pada sesuatu yang bersifat positif dan bermanfaat.

Selain minimnya kegiatan bersama diantara warga perumahan, berdasarkan hasil penelitian sebelumnya diperoleh data yang menunjukkan bahwa warga sebagian besar merupakan masyarakat dengan kategori masyarakat berpenghasilan rendah. Berdasarkan Permenpera Nomor 5/Permen/M/2007, kriteria MBR berdasarkan penghasilan masyarakat yang dikelompokkan menjadi tiga kelompok sasaran. Penghasilan yang dimaksud adalah penghasilan yang didasarkan atas gaji pokok ataupun pendapatan perbulan. Sasaran pertama yaitu masyarakat yang memiliki penghasilan Rp 1.700 .000 sampai dengan Rp 2.500.000. Kategori kedua yaitu masyarakat yang memiliki penghasilan Rp 1.000.000 hingga Rp 1.700.000. Sedangkan kategori ketiga yaitu masyarakat yang memiliki penghasilan penghasilan kurang dari Rp 1.000.000. Keterangan lain juga dapat dilihat berdasarkan Permenpera Nomor 27 Tahun 2012 dan Permenpera Nomor 28 Tahun 2012 disebutkan bahwa yang dimaksud dengan MBR adalah masyarakat yang memiliki penghasilan Rp 3.500.000 < Pengahasilan $<$ Rp5.500.000.

Kondisi masyarakat berpenghasilan rendah pada dasarnya memiliki berbagai kerentanan. Selain rentan dalam hal ekonomi, masyarakat berpenghasilan rendah juga rentan terhadap ketahanan pangan. Ketahanan pangan disini yaitu tersedianya pangan yang bergizi dan aman untuk kesehatan dalam jumlah yang cukup Kondisi masyarakat berpenghasilan rendah ini dapat menimbulkan ketidakmampuan dalam pemenuhan kebutuhan pangan tersebut. Selain itu, pengetahuan masyarakat terhadap ketahanan pangan juga masih tergolong minim. Kondisi seperti inilah yang semakin memperlemah masyarakat dalam upaya peningkatan ketahanan pangan tersebut.

Berdasarkan dua kondisi tersebut, perlu upaya yang inovatif dan kreatif untuk mewujudkan interaksi positif sesama warga perumahan sekaligus upaya peningkatan ketahanan pangan. Solusi yang ditawarkan dalam PPM ini yaitu Pelatihan Peningkatan Gizi Keluarga Sebagai Upaya Mengatasi Masalah Stunting Dengan Pemanfaatan Pekarangan di Desa Cinunuk Kecamatan Cileunyi Kabupaten Bandung.

\section{METODE}

Metode pelaksanaan kegiatan PPM ini dilakukan melalui sebuah proses sistematis mulai dari tahap assessment, pelaksanaan program hingga monitoring dan evaluasi. Kegiatan PPM ini dilaksanakan dari mulai bulan Juni sampai bulan September 2018 dan bertempat di Desa Cinunuk Kecamatan Cileunyi Kabupaten Bandung. Khalayak sasaran yang dipilih dalam kegiatan PPM ini yaitu Karang Taruna dan PKK. Pemilihan lokasi dan kelompok sasaran ini yaitu berdasarkan hasil penelitian sebelumnya didapatkan data bahwa masih kurangnya pengetahuan dan keterampilan kelompok sasaran dalam kegiatan pemanfaatan pekarangan sebagai upaya peningkatan gizi keluarga. Kemudian juga tidak ada kegiatan bersama yang dilakukan secara rutin, yang 


\begin{tabular}{|c|c|c|c|c|}
\hline $\begin{array}{c}\text { Prosiding Penelitian \& } \\
\begin{array}{c}\text { Pengabdian Kepada } \\
\text { Masyarakat }\end{array}\end{array}$ & $\begin{array}{c}\text { e ISSN : 2581-1126 } \\
\text { p ISSN : 2442-448X }\end{array}$ & Vol 5, No: 3 & Hal: 260 - 264 & Desember 2018 \\
\hline
\end{tabular}

menyebabkan interaksi sosial di perumahan tergolong kurang. Serta banyak pemuda dan Ibu-Ibu yang memiliki waktu luang yang banyak yang dapat dimanfaatkan dengan berbagai kegiatan yang produktif.

Program Pengabdian Kepada Masyakat ini akan diawali dengan kegiatan assessment, kemudian dilanjutkan dengan pelaksanaan kegiatan pelatihan pemanfaatan pekarangan sebagai upaya peningkatan gizi keluarga. Kegiatan pelatihan ini akan dipandu oleh narasumber (tenaga ahli) sebagai fasilitator dan dibantu dengan seperangkat alat untuk melakukan simulasi atau praktik secara langsung. Sebelum kegiatan pelatihan dilakukan, terdapat beberapa kegiatan berupa persiapan yang perlu dilakukan, kemudian melakukan evaluasi kegiatan pelatihan maupun evaluasi secara keseluruhan yang dilakukan pasca pelatihan. Berikut ini merupakan tabel rincian kegiatan yang akan dilakukan dalam Program Pengabdian Kepada Masyarakat ini beserta peran keterlibatan Dosen, Mahasiswa KKN dan Masyarakat dalam kegiatan.

Tabel 1 Rincian Kegiatan PPM

\begin{tabular}{|c|c|c|c|c|}
\hline \multirow[b]{2}{*}{$\begin{array}{l}\text { No } \\
\text {. }\end{array}$} & \multirow[b]{2}{*}{$\begin{array}{l}\text { Rencana } \\
\text { Kegiatan }\end{array}$} & \multicolumn{3}{|c|}{ Keterlibatan dalam kegiatan } \\
\hline & & Dosen & $\begin{array}{c}\text { Mahasiswa } \\
\text { KKN }\end{array}$ & $\begin{array}{c}\text { Masyaraka } \\
\text { t }\end{array}$ \\
\hline 1. & $\begin{array}{l}\text { Persiapan } \\
\text { kegiatan } \\
\text { PPM. }\end{array}$ & $\begin{array}{l}\text { Membuat } \\
\text { proposal dan } \\
\text { mencari data } \\
\text { awal wilayah. }\end{array}$ & $\begin{array}{l}\text { Bersama } \\
\text { dosen ke } \\
\text { lapangan } \\
\text { untuk } \\
\text { melakukan } \\
\text { assessment. }\end{array}$ & $\begin{array}{l}\text { Sebagai } \\
\text { narasumber. }\end{array}$ \\
\hline 2. & $\begin{array}{l}\text { Pemetaan } \\
\text { wilayah. }\end{array}$ & $\begin{array}{l}\text { Mempelajari } \\
\text { secara lebih } \\
\text { mendalam } \\
\text { mengenai } \\
\text { potensi- } \\
\text { potensi di } \\
\text { Perumahan } \\
\text { Permata } \\
\text { Hijau, yaitu } \\
\text { potensi yang } \\
\text { dapat } \\
\text { dimanfaatkan } \\
\text { dalam } \\
\text { kegiatan PPM } \\
\text { ini. }\end{array}$ & $\begin{array}{l}\text { Tenaga } \\
\text { lapangan } \\
\text { pelaksana } \\
\text { pemetaan. }\end{array}$ & $\begin{array}{l}\text { Sebagai } \\
\text { narasumber. }\end{array}$ \\
\hline 3. & $\begin{array}{l}\text { Pelaksana } \\
\text { an } \\
\text { pelatihan. }\end{array}$ & $\begin{array}{l}\text { Melaksanakan } \\
\text { proses } \\
\text { pelatihan. }\end{array}$ & $\begin{array}{l}\text { Membantu } \\
\text { proses } \\
\text { administrasi } \\
\text { dan proses } \\
\text { pelaksanaan } \\
\text { pelatihan. }\end{array}$ & $\begin{array}{l}\text { Menjadi } \\
\text { peserta } \\
\text { pelatihan. }\end{array}$ \\
\hline
\end{tabular}

\begin{tabular}{|l|l|l|l|l|}
\hline 4. & Monitoring & Melakukan & Mengumpulk & Memberikan \\
& dan & pengkajian & an informasi \\
evaluasi. & $\begin{array}{l}\text { dan } \\
\text { pengukuran } \\
\text { keberhasilan } \\
\text { dari pelatihan. }\end{array}$ & $\begin{array}{l}\text { kebermanfaa } \\
\text { tan } \\
\text { pelatihan. }\end{array}$ & $\begin{array}{l}\text { mengenai } \\
\text { kebermanfa } \\
\text { atan } \\
\text { pelatihan. }\end{array}$ \\
\hline
\end{tabular}

Setiap kegiatan tentunya harus memiliki tujuan dan manfaat, demikian juga dalam kegiatan Program Pengabdian Kepada Masyarakat ini memiliki tujuan dan manfaat yang perlu untuk diwujudkan melalui tahapan dan proses yang sistemantis dan terukur. Berikut ini merupakan indikator keberhasilan kegiatan dalam Program Pengabdian Kepada Masyarakat ini.

Tabel 2 I ndikator Keberhasilan

\begin{tabular}{|c|c|c|c|}
\hline No. & I ndikator & $\begin{array}{l}\text { Base line } \\
\text { (sebelum } \\
\text { kegiatan) }\end{array}$ & $\begin{array}{c}\text { Pencapaian } \\
\text { Setelah Kegiatan }\end{array}$ \\
\hline 1. & Pengetahuan & $\begin{array}{l}\text { Kelompok sasaran } \\
\text { sedikit mengetahui } \\
\text { tentang kegiatan } \\
\text { pemanfaatan } \\
\text { pekarangan sebagai } \\
\text { upaya peningkatan } \\
\text { gizi keluarga. }\end{array}$ & $\begin{array}{lr}\text { Kelompok sasaran } \\
\text { mengetahui dan } \\
\text { memahami tentang } \\
\text { kegiatan } \\
\text { pemanfaatan } \\
\text { pekarangan } \\
\text { sebagai r upaya } \\
\text { peningkatan gizi } \\
\text { keluarga. }\end{array}$ \\
\hline 2. & Keterampilan & $\begin{array}{l}\text { Kelompok sasaran } \\
\text { belum mampu secara } \\
\text { maksimal dalam } \\
\text { melakukan kegiatan } \\
\text { pemanfaatan } \\
\text { pekarangan sebagai } \\
\text { upaya peningkatan } \\
\text { gizi keluarga. }\end{array}$ & $\begin{array}{l}\text { Kelompok sasaran } \\
\text { mampu melakukan } \\
\text { kegiatan } \\
\text { pemanfaatan } \\
\text { pekarangan } \\
\text { sebagai upaya } \\
\text { peningkatan gizi } \\
\text { keluarga. }\end{array}$ \\
\hline 3. & Motivasi & $\begin{array}{l}\text { Sudah ada motivasi } \\
\text { dari kelompok } \\
\text { sasaran dalam } \\
\text { melakukan kegiatan } \\
\text { pemanfaatan } \\
\text { pekarangan sebagai } \\
\text { upaya peningkatan } \\
\text { gizi keluarga. }\end{array}$ & $\begin{array}{l}\text { Kelompok sasaran } \\
\text { lebih termotivasi } \\
\text { untuk melakukan } \\
\text { kegiatan } \\
\text { pemanfaatan } \\
\text { pekarangan } \\
\text { sebagai rapaya } \\
\text { peningkatan gizi } \\
\text { keluarga. }\end{array}$ \\
\hline
\end{tabular}

Terakhir, sebagai bagian dari tahapan kegiatan PPM, juga akan dilakukan monitoring dan evaluasi dalam kegiatan PPM ini akan dilakukan baik oleh dosen maupun mahasiswa. Tim dosen berperan dalam melakukan pengkajian dan pengukuran keberhasilan dari pelatihan sesuai dengan indikator keberhasilan yang telah ditentukan sebelumnya. Sedangkan peran mahasiswa yaitu mengumpulkan informasi kebermanfaatan pelatihan dari para peserta pelatihan. 


\begin{tabular}{|c|c|c|c|c|}
\hline $\begin{array}{c}\text { Prosiding Penelitian \& } \\
\begin{array}{c}\text { Pengabdian Kepada } \\
\text { Masyarakat }\end{array}\end{array}$ & $\begin{array}{c}\text { e ISSN : 2581-1126 } \\
\text { p ISSN : 2442-448X }\end{array}$ & Vol 5, No: 3 & Hal: 260 - 264 & Desember 2018 \\
\hline
\end{tabular}

\section{HASIL KEGIATAN}

\section{Hasil Assessment}

Berdasarkan hasil assessment yang telah dilakukan, diperoleh data bahwa kegiatan Ibu PKK dan Ibu pengajian cukup aktif dilakukan dengan beberapa agenda rutin seperti pemeriksaan kesehatan di posyandu, kegaitan pengajian, arisan, kegiatan pada lingkup RW seperti kerja bakti, dll. Sementara itu, kegiatan Karang Taruna dan Remaja Mesjid juga tidak hanya aktif pada PHBN dan PHBI saja namun juga aktif dalam kegiatan sehari-hari seperti kerja bakti di lingkungan RW, kegiatan pengajian, dll. Kegiatan PKK, Karang Taruna dan Remaja Mesjid sering kali difokuskan di Mesjid Al-Hikmah selain bertujuan untuk menjaga agar setiap kegiatan berlandaskan agama, hal ini juga bertujuan agar seluruh elemen masyarakat selalu berusaha dan berpartisipasi dalam memakmurkan Mesjid.

\section{Pelaksanaan Kegiatan}

Judul kegiatan PPM ini yaitu "Pelatihan Peningkatan Gizi Keluarga Sebagai Upaya Mengatasi Masalah Stunting (Masalah Kekurangan Gizi) Dengan Pemanfaatan Pekarangan”. Pelatihan ini dihadiri oleh 61 orang peserta yang berasal dari Ibu-Ibu PKK dan Ibu-Ibu pengajian Mesjid Al-Hikmah Desa Cinunuk Kabupaten Bandung. Selain itu, turut hadir dalam kegiatan PPM ini yaitu Ketua dan pengurus DKM Mesjid Al-Hikmah serta Ketua RW 05 Desa Cinunuk. Kegiatan PPM dilaksanakan pada hari Minggu, 12 Agustus 2018 pukul 13.00-15.30 WIB bertempat di Mesjid Al-Hikmah Desa Cinunuk Kabupaten Bandung. Narasumber dalam pelatihan ini yaitu Ibu Dr. Tina Rostinawati, A.Pt yang merupakan salah satu staff pengajar di Fakultas Farmasi Universitas Padjadjaran.

Secara teknis pelatihan dilakukan dengan menggunakan metode andragogi yaitu pelatihan yang khusus dilakukan untuk orang dewasa. Tahapan pelatihan yaitu dimulai dengan tahapan persiapan, mulai dari persiapan perlengkapan pelatihan seperti pemasangan infokus, penyiapan konsumsi bagi peserta pelatihan dan setting tempat pelatihan. Pelatihan dibuka oleh MC yang berasal dari Tim PPM yaitu Maulana Irfan, S.Sos., M.I.Kom. Setelah pembukaan, acara dilanjutkan dengan sambutan dari Ketua Tim PPM Dr. Soni Akhmad Nulhaqim, S.Sos., M.Si, sambutan dari Ketua DKM Mesjid AlHikmah dan sambutan dari Ketua RW 05 Desa Cinunuk. Setelah sambutan, acara dilanjutkan dengan pengisian kuisioner yang dipandu secara langsung oleh tim PPM. Sebelum masuk pada acara inti, MC mengajak para peserta untuk melakukan energizer berupa games sederhana yang bertujuan untuk meningkatkan fokus dan menarik perhatian para peserta pada saat pemberian materi.

Materi pelatihan yang diberikan yaitu materi terkait "Makanan Sehat dan Bergizi". Setelah pemaparan materi oleh narasumber, acara berikutnya yaitu tanya jawab antara peserta pelatihan dengan narasumber. Acara terakhir yaitu kristalisasi materi oleh MC dan penutupan.

\section{SIMPULAN}

Secara umum, peserta pelatihan belum mengetahui apa itu makanan sehat dan bergizi.

\section{UCAPAN TERIMA KASIH}

Ucapan terima kasih disampaikan kepada editor dan mitra bestari, yang telah memberikan masukan-masukan demi kesempurnaan artikel ini. Kepada pengelola jurnal, yang telah memberikan kesempatan untuk menerbitkan artikel kami. Kemudian, kepada rekan dosen di lingkungan FISIP Unpad yang telah menyediakan waktu untuk berdisikusi untuk mendalami hasil penelitian yang ditulis ke dalam artikel ini.

\section{REFERENSI}

Peraturan Menteri Negara Perumahan Rakyat Nomor: 05/Permen/M/2007 Tentang Pengadaan Perumahan Dan Permukiman Dengan Dukungan Fasilitas Subsidi 
Perumahan Melalui Kprs/Kprs Mikro Bersubsidi.

Peraturan Menteri Perumahan Rakyat Republik Indonesia Nomor 27 Tahun 2012 Tentang Pengadaan Perumahan Melalui Kredit/Pembiayaan Pemilikan Rumah Sejahtera Dengan Dukungan Fasilitas Likuiditas Pembiayaan Perumahan.

Peraturan Menteri Perumahan Rakyat Republik Indonesia Nomor 28 Tahun 2012 Tentang Petunjuk Pelaksanaan Pengadaan Perumahan Melalui Kredit/Pembiayaan Pemilikan Rumah Sejahtera Dengan Dukungan Fasilitas Likuiditas Pembiayaan Perumahan. 